\title{
Spatiotemporal expression pattern of progranulin in embryo implantation and placenta formation suggests a role in cell proliferation, remodeling, and angiogenesis
}

\author{
Joëlle A Desmarais, Mingju Cao ${ }^{1}$, Andrew Bateman ${ }^{1}$ and Bruce D Murphy
}

Centre de Recherche en Reproduction Animale, Faculté de Médecine Vétérinaire, Université de Montréal, 3200 Sicotte, St-Hyacinthe, Québec, Canada J2S 7C6 and ${ }^{1}$ Endocrine Research Laboratories, Department of Medicine, Royal Victoria Hospital, McGill University, 687 ave. des Pins Ouest, Room L2.05, Montreal, Quebec, Canada H3A 1 A1

Correspondence should be addressed to J A Desmarais; Email: joelle.desmarais@umontreal.ca

J A Desmarais and M Cao contributed equally to this work

\begin{abstract}
Embryo implantation in the mink is preceded by a variable but obligate period of delay in development. Under the influence of progesterone and unknown luteal factors, the mink embryo implants 11-13 days following its exit from diapause. Recent work suggests that progranulin, a growth factor and secreted glycoprotein, is involved in trophoblast proliferation, placental development and endometrial differentiation in the mouse. Using the mink model of delayed implantation and endotheliochorial placentation, we examined the spatiotemporal distribution of progranulin in trophoblast and endometrium during pre- and early post-implantation gestation in vivo. A partial sequence of the mink progranulin gene was cloned and sequenced. Comparative sequence analysis revealed that exons 1 and 2 of mink progranulin share 86.6, 82.4, and 94.9\% of nucleic acid sequence identity with the human, mouse, and dog sequences respectively, and indicated that the invariable residues of the cysteine-rich motifs of progranulin are well conserved in the mink sequence. By in situ hybridization, we show that mink progranulin transcript is present in the cytotrophoblast and in epithelial and stromal endometrial cells at the site of implantation and during early placental formation. Immunohistochemistry revealed the progranulin protein to be strongly expressed in endometrial luminal and glandular epithelium around the time of implantation. In the incipient labyrinth, progranulin expression is localized to cytotrophoblasts and fetal capillaries, as well as to the hypertrophied maternal endothelial cells. This study demonstrates that high levels of progranulin expression correspond to active cell proliferation, remodeling, and angiogenesis occurring during the establishment of the placenta in the mink.
\end{abstract}

Reproduction (2008) 136 247-257

\section{Introduction}

Embryo implantation in the mink is preceded by an obligate delay in the development of variable length, occurring at the blastocyst stage (Hansson 1947, Enders 1952). This delay is terminated by lengthening of the photoperiod associated with the vernal equinox, which occurs in March in the Northern hemisphere (Enders 1952, Duby \& Travis 1972, Murphy \& James 1974, Martinet et al. 1981, Sundqvist et al. 1988). The proximal event in termination of pre-implantation delay is the secretion of prolactin that reinitiates corpus luteum $(\mathrm{CL})$ development and the uterine-priming progesterone secretion (Papke et al. 1980, Martinet et al. 1981, Murphy et al. 1981, Lopes et al. 2004). Resumption of embryo development in the mink is characterized by renewed nucleic acid and protein synthesis by trophoblast and ICM cells of the blastocyst, accompanied by a logarithmic increase in blastocyst diameter (Desmarais et al. 2004). Under the influence of progesterone and unknown luteal factors, the mink embryo implants 11-13 days following its exit from diapause (Murphy et al. 1983, Desmarais et al. 2004) and post-implantation gestation requires an invariable 30 days (Hansson 1947, Murphy \& James 1974).

As described in the ferret (Mustela putorius) and the spotted skunk (Spilogale gracilis), mustelid implantation is achieved by penetration of the endothelial epithelium by trophoblast cells in early stages of differentiation (Enders \& Schlafke 1972, Enders \& Mead 1996). Following trophoblast attachment in the ferret, the syncytiotrophoblast cells invade the endometrial tissue and the endometrial glands are progressively transformed into a maternal symplasma as the syncytiotrophoblast advances (Gulamhusein \& Beck 1973, 1975). 
During syncytiotrophoblast invasion, the cytotrophoblast proliferates to eventually form the chorionic villi (Gulamhusein \& Beck 1973, 1975). In the mink, placenta is villous and endotheliochorial (Enders 1952, Krebs et al. 1997), less invasive than mouse or human hemochorial placenta, as the blood vessels of the mother become surrounded by trophoblast but are not destroyed (Steven 1975). In the labyrinth region of the placenta, extremely enlarged maternal endothelial cells can be observed (Jones et al. 1997, Backlin et al. 1998). This phenomenon also appears in other carnivores, but it is more pronounced in mink (Jones et al. 1997, Krebs et al. 1997, Backlin et al. 1998).

Recent work suggests that progranulin, a secreted glycoprotein and a growth factor, is involved in mouse trophoblast proliferation (Diaz-Cueto et al. 2000, Qin et al. 2005), placental development, and endometrial decidualization (Daniel et al. 2003). Progranulin, also known as granulin-epithelin precursor (Zanocco-Marani et al. 1999), proepithelin (Plowman et al. 1992), PC cellderived growth factor (Zhou et al. 1993), or acrogranin (Baba et al. 1993), is a 66-88 kDa protein (Zhou et al. 1993) comprising 7.5 granulin/epithelin consensus sequences, each of these consisting of a conserved 12-cysteine motif (Bhandari et al. 1992). The granulin/ epithelin domains of progranulin are unique and therefore progranulin cannot be classified into any known growth factor families, although a distant common origin with epidermal growth factor (EGF)/transforming growth factor- $\alpha$ (TGF $\alpha$ ) family of growth factors has been suggested (Hrabal et al. 1996, Bateman \& Bennett 1998). Progranulin expression is found across virtually all tissues in mammals (Baba et al. 1993a, 1993b, Bhandari et al. 1993, Daniel et al. 2000). Abundant transcript expression is found in rapidly dividing epithelia, i.e., keratinocytes or enterocytes from the deep crypt of the digestive tract (Daniel et al. 2000), suggesting a role in epithelial proliferation. Progranulin has also been associated with tumor progression and invasiveness in adrenocortical carcinomas (He et al. 2002), glioblastomas (Liau et al. 2000), renal carcinomas (Donald et al. 2001), and ovarian as well as breast cancers (Jones et al. 2003, Tangkeangsirisin et al. 2004, Tangkeangsirisin \& Serrero 2004). Moreover, mutations in the progranulin gene were found to cause neurodegenerative frontotemporal dementia, suggesting roles for progranulin in the maintenance of healthy neurons (Baker et al. 2006, Cruts et al. 2006).

Progranulin transcripts have been detected in rodent oocytes, spermatocytes, and spermatogonia (Daniel et al. 2000, Diaz-Cueto et al. 2000, Suzuki \& Nishiahara 2002) and have been found in the embryo throughout pre-implantation development (Diaz-Cueto et al. 2000, Qin et al. 2005). After fertilization, the levels of progranulin mRNA slowly decline until the four-cell stage embryo in the mouse and rise again in the eightcell stage embryo (Diaz-Cueto et al. 2000). Progranulin can promote mouse blastocyst formation by enhancing trophoblast proliferation, blastocyst cavitation, and expansion (Diaz-Cueto et al. 2000, Qin et al. 2005). Progranulin also stimulates hatching, adhesion, and outgrowth of the mouse blastocyst in vitro (Qin et al. 2005). In the post-adhesion blastocyst, progranulin mRNA becomes more abundant than in the preadhesion blastocyst (Qin et al. 2003). Furthermore, the progranulin expression in the mouse is strongly induced in the primary giant cells of the placenta and in the decidual cells of the maternal endometrium (Daniel et al. 2003).

In vitro studies conducted on mouse blastocysts suggest that progranulin acts as a key player in embryo implantation and placental development, but there is a lack of direct confirmation in the literature. We therefore employed the mink model of delayed implantation and endotheliochorial placentation to investigate the expression of progranulin in trophoblast and endometrium during embryo implantation in vivo.

\section{Results}

\section{Cloning and sequence analysis of mink progranulin partial CDNA}

A partial sequence $(214 \mathrm{bp})$ of the mink progranulin gene was cloned and sequenced, and sequence homology between the mink and three other mammalian species was determined. In Fig. 1, the mink progranulin sequence is presented as well as the comparison among four mammalian progranulin sequences. This analysis revealed that mink progranulin exons 1 and 2 share $86.6 \%$ of nucleic acid sequence identity with the human, $82.4 \%$ with the mouse, and $94.9 \%$ with the dog, a closely related carnivore species. The partial amino acid sequence was deduced from the cDNA and compared with human, dog, and mouse sequences (Fig. 2). Exons 1 and 2 encode for two hemidomains of highly conserved granulin/epithelin motifs, the C-terminal region of paragranulin and the $\mathrm{N}$-terminal region of Granulin G (Bhandari et al. 1992). As expected, the mink sequence contained all the conserved cysteine residues of the cysteine-rich motifs found in human, dog, and mouse sequences, as well as the other invariant serine, proline, and glycine residues (Fig. 2, Bhandari et al. 1992).

\section{Progranulin mRNA is expressed in mink endometrial and trophoblastic tissues around the time of implantation}

To investigate the spatiotemporal pattern of progranulin mRNA expression in the endometrial and trophoblastic tissues around the time of implantation in the mink, we employed in situ hybridization. Nine days after 


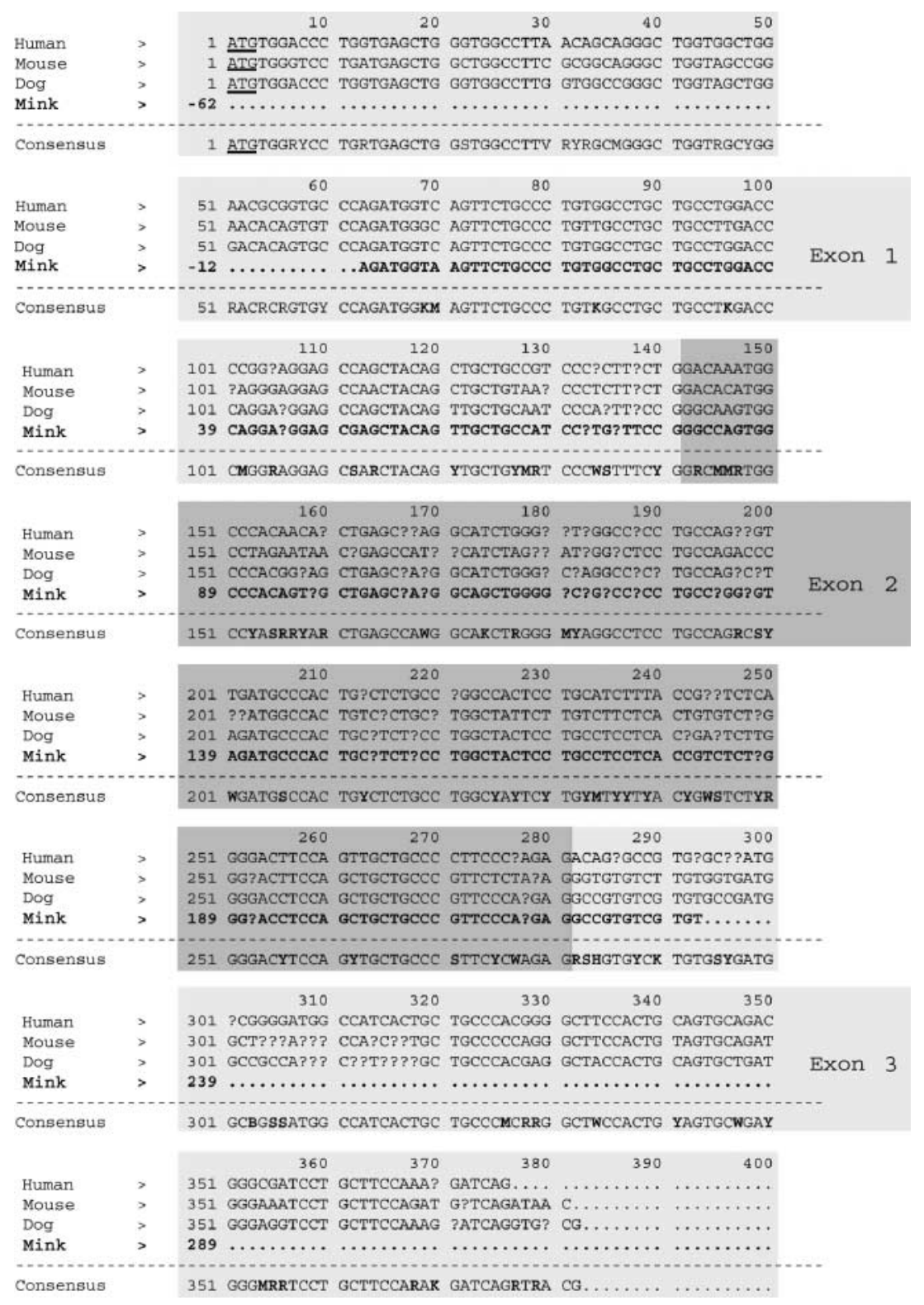

Figure 1 Partial cDNA sequence of mink progranulin, and consensus between human, dog, mouse, and mink progranulin sequences. In homology with the human progranulin gene sequence, the mink partial cDNA sequence for progranulin spans exons 1-3 (light and dark gray boxes) and encompasses $214 \mathrm{bp}$. This region contains two granulin/epithelin hemidomains of progranulin, and its sequence is highly conserved among human, dog, mouse, and mink species. The start codons are underlined. The mink sequence shares $86.6 \%$ of identity with the human, $82.4 \%$ with the mouse, and $94.9 \%$ with the dog. termination of embryonic diapause by exogenous prolactin treatment, but before implantation, there is a strong hybridization signal indicative of progranulin mRNA expression in the mink uterus, throughout the endometrial epithelium (both luminal and glandular, Fig. 3a). On the day of implantation, when the trophoblast makes contact with the maternal epithelium, progranulin mRNA was clearly expressed in the invading trophoblast (Fig. 3c). There is also notable expression in the transforming glandular epithelium and in the stroma, at the blastocyst localization (Fig. 3e and f). During villi formation in the incipient placenta, progranulin mRNA expression is observed mainly in the cytotrophoblast cells, which are actively undergoing cell division to form the chorionic villi (Fig. 3h). This expression is evident in the basal and transformed endometrial glands as well
(Fig. 3i). Sense control hybridizations (Fig. 3b, d, g and j) revealed no non-specific signal.

\section{Progranulin protein is expressed in mink endometrial and trophoblastic tissues around the time of implantation}

To correlate progranulin mRNA expression with expression of the protein, immunohistochemistry was conducted in mink endometrial and trophoblastic tissues around the time of implantation. In the mink uterus, 9 days after termination of embryonic diapause by exogenous prolactin treatment, but prior to implantation, progranulin protein is present in the cytoplasm of the cells of the endometrial glands as well as the luminal epithelium (Fig. 4a and b). The day of embryo 


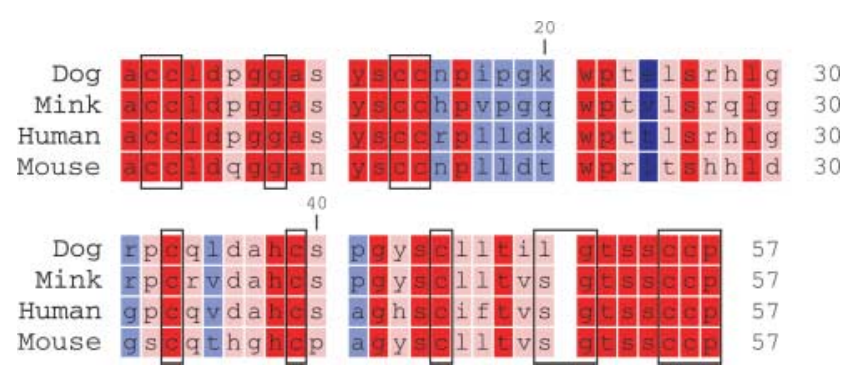

Figure 2 Alignment and comparison of the mouse, human, dog, and mink deduced partial amino acid sequences. The single-letter code identifies the amino acids. Perfect (100\%) homology is indicated in red, residues occuring three times are indicated in pink, residues occuring two times are colored in light blue, and four different residues are indicated in dark blue. Amino acids 1 to 30 correspond to the Cterminal fragment of paragranulin, and amino acids 31 to 57 to the $\mathrm{N}$ terminal fragment of granulin G. The highly conserved residues found in the cystein-rich motifs of progranulin sequence are delineated by boxes. It is noteworthy that all the boxed residues are well conserved in the four species analyzed, including the mink. implantation (day 0), the uterine glands undergo hypertrophy and elongation, while the trophoblast makes contact with the maternal epithelium. Progranulin protein is highly expressed in the trophoblast cells (Fig. 4d) as well as in the transformed epithelium of the glands, and in the stroma surrounding the glands (Fig. 4f). At this time, progranulin protein is also present in the intact basal glands. While progranulin expression is absent in the maternal blood vessels located near these basal glands, it is otherwise present in the blood vessels in the transformed gland area (Fig. 4h, arrowheads), indicating that progranulin is preferentially expressed in the newly formed maternal blood vessels. Together, these results suggest that progranulin is involved in implantation during trophoblast attachment, endometrial transformations, endometrial gland proliferation, and maternal angiogenesis.

As trophoblast invasion proceeds, the chorionic villi are formed in the incipient labyrinth of the placenta.
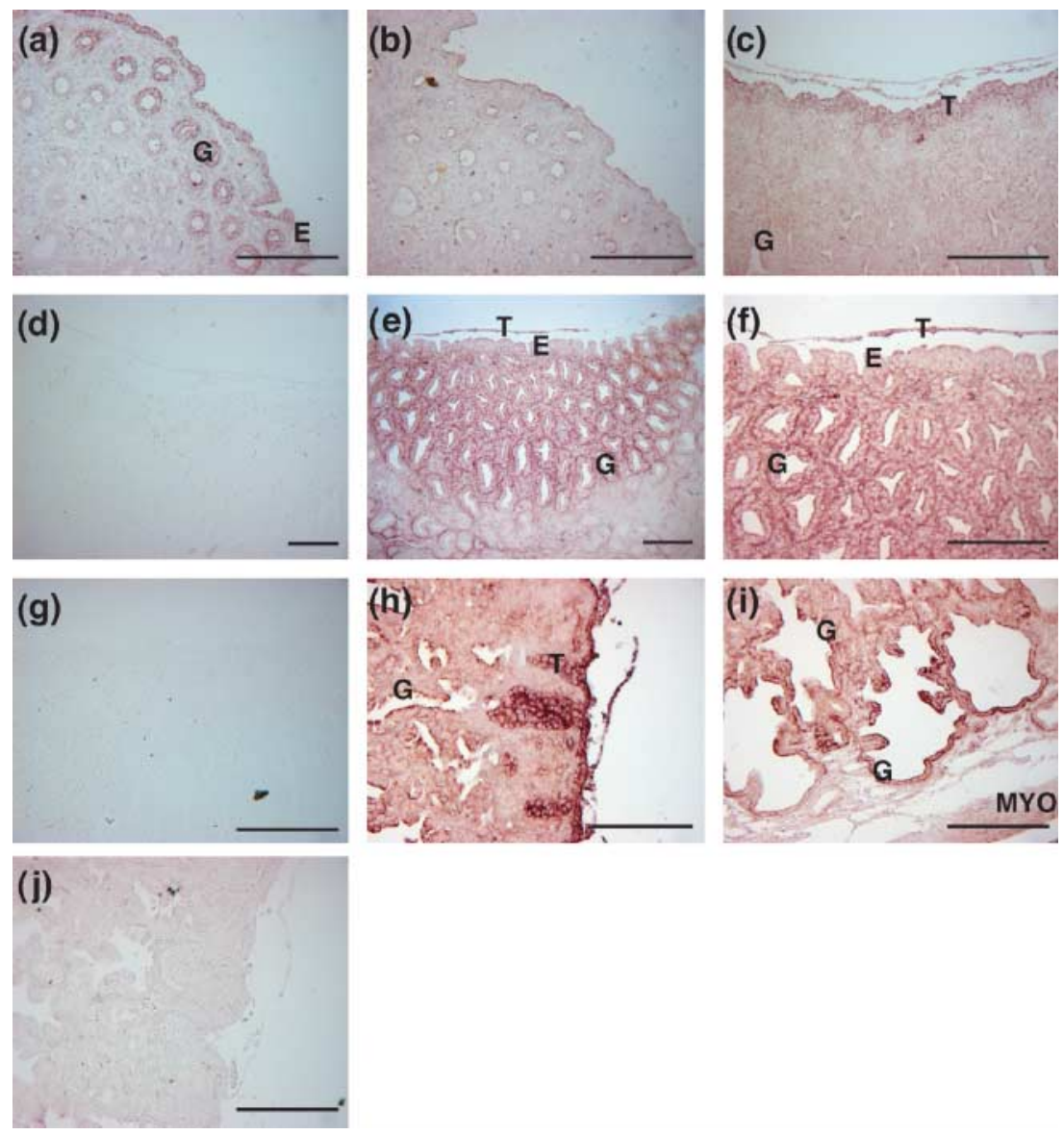

Figure 3 Progranulin mRNA is expressed in mink trophoblast and endometrium around the time of embryo implantation. In situ hybridization was performed with (a, c, e, f, h and i) antisense or (b, d, g and j) sense (control) probe for progranulin mRNA. (a and b) Prolactin-activated mink uterus, before implantation occurs. There is pronounced mRNA expression in luminal and glandular endometrial epithelium. (c and d) Early implanted stage uterus. Strong expression of progranulin transcript is observed in the trophoblast cells. (e-g) Early implanted stage uterus, during trophoblast apposition. (e) Progranulin transcript is strongly induced in glandular epithelium undergoing transformation, and (f) the cytoplasmic localization of progranulin transcript in the glandular epithelium and in the stroma can be appreciated at a higher magnification. (h-j) During villi formation in the incipient labyrinth, progranulin hybridization signal is most intense in cytotrophoblast cells of the embryo (h). There is also a positive signal in the transformed and basal endometrial glands (i). E, luminal epithelium; G, glandular epithelium; T, trophoblast; MYO, myometrium. Bars: $200 \mu$ m. 

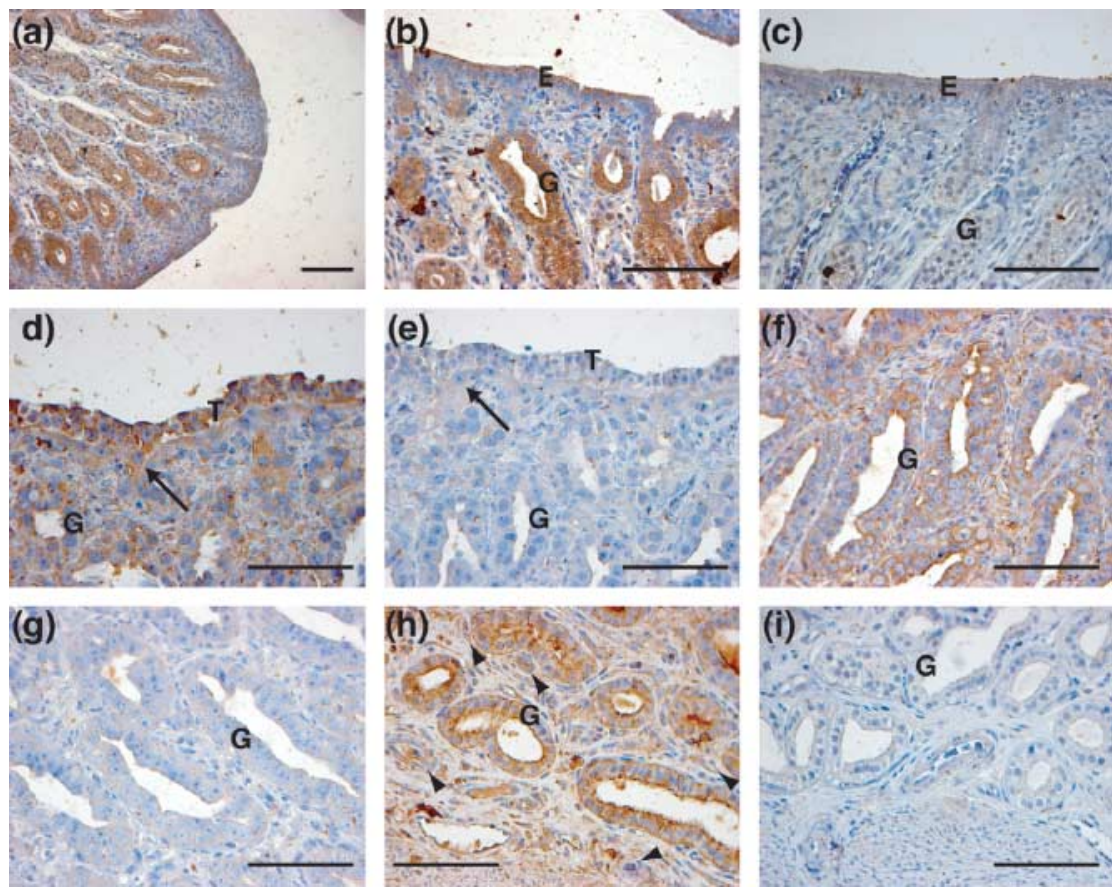

Figure 4 Progranulin protein is expressed in the trophoblast and endometrial cells in the mink pre-implantation and early implanted uterus. To detect progranulin protein by immunohistochemistry, $(a, b, d, f$ and $h)$ immune rabbit serum against human progranulin or (c, e, $g$ and i) pre-immune rabbit serum (control) were employed. (a-c) In the prolactin-activated mink uterus, progranulin protein is present in the endometrial glands (a), and at higher magnification (b), we can detect the presence of progranulin protein in the cytoplasm of the luminal epithelium. (d, e, f, g, h and i) Early implantation sites. Progranulin protein was detected in the trophoblast, including the cytotrophoblast and the syncytiotrophoblast (d), in the transforming glandular epithelium and surrounding stroma ( $f$ ), as well as in the intact basal glands and in the maternal blood vessels, at different intensities ( $h$ ). E, Luminal epithelium; G, glandular epithelium; T, trophoblast; arrow, syncytiotrophoblast; arrowheads, maternal blood vessels. Bars: $100 \mu \mathrm{m}$.

Progranulin protein remains elevated in the cytotrophoblast during the first days following implantation (days 1 and 2, Fig. $5 \mathrm{a}$ and $\mathrm{b}$ respectively). Some expression is also clearly discernable in the syncytiotrophoblast as it progresses into the maternal endometrium (Fig. 5a). Progranulin expression can be continuously observed in the transformed (Fig. $5 \mathrm{~d}$ and g) and intact endometrial glands (Fig. 5c and g), and at a lower degree in the stroma (Fig. 5c and d). As above, the progranulin expression in the cytotrophoblast of the forming villi suggests a role for progranulin in cytotrophoblast proliferation.

Five days after implantation, in the early placenta, the four layers composing the mink endotheliochorial placenta (allantochorionic, labyrinth, junctional, and basal) are discernable. The labyrinth is composed of the chorionic villi, the fetal mesenchyme, and the fetal blood and maternal blood vessels, which are constituted of hypertrophied endothelial cells. Progranulin protein is present in high concentrations in the newly formed maternal hypertrophied endothelial cells (Fig. 6a and b). Furthermore, progranulin immunoreactivity is observed in the cytotrophoblast cells composing the chorionic villi and in the fetal capillaries of the mesenchymal core of the villi, but in the syncytiotrophoblast cells surrounding the cytotrophoblast, the signal is much weaker (Fig. 6a and b). In the elongated glands and the stromal cells from the junctional zone, progranulin has become less expressed (Fig. $6 \mathrm{~d}$ and e), while in the intact glands from the basal glandular zone, progranulin is still present (Fig. $6 \mathrm{~d}$ and e). This pattern of expression for progranulin protein suggests that progranulin is involved in the establishment of the labyrinth and in maternal as well as fetal angiogenesis in the mink placenta.

\section{Discussion}

We used the mink model of endotheliochorial placentation to follow progranulin mRNA and protein expression pattern in pre- and early post-implantation events, and during early development of the placenta. This investigation provides the first evidence for the expression of progranulin in the trophoblast and the endometrium at the time of embryo implantation in vivo. Furthermore, the data obtained in this study suggest a new role for progranulin in the establishment of fetal villi and maternal and fetal vascular components in the endotheliochorial placenta of the mink.

\section{Mink progranulin partial cDNA sequence}

Herein, we report the partial cDNA and deduced amino acid sequences for mink progranulin. Comparative 

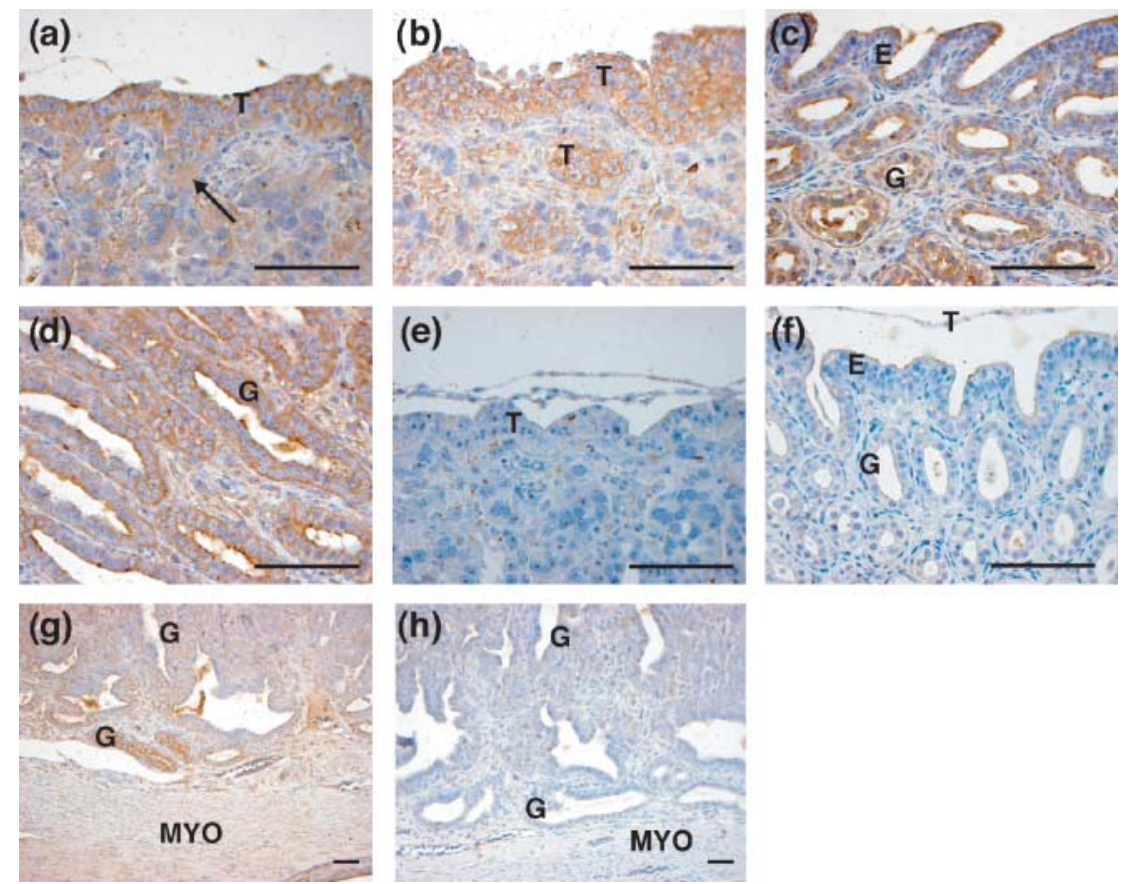

Figure 5 Progranulin protein localizes in the mink endometrium and trophoblast during the early post-implantation period. To detect progranulin protein by immunohistochemistry, either $(a, b, c, d$ and $g$ ) rabbit serum against human progranulin or (e, $f$ and $h$ ) pre-immune rabbit serum (control) were employed. (a and e) In the implantation site, 1 day after implantation, progranulin protein is detected in the cytotrophoblast and in the syncytiotrophoblast invading the maternal endometrium. (b, c, d, f, g and h) The implantation site, 2 days after implantation, when the trophoblast initiates the chorionic villi formation. An immunopositive signal indicating the presence of progranulin in the trophoblast (b), in the luminal epithelium, and in the glandular epithelium of rounded (c), or elongated (d) glands. The signal is also present in the intact basal glands at the implantation site (g) and in the stroma (d). E, luminal epithelium; G, glandular epithelium; T, trophoblast; MYO, myometrium; arrow,

syncytiotrophoblast. Bars: $100 \mu \mathrm{m}$.

analysis shows that exons 1 and 2 are highly conserved among mink, dogs, mice, and humans, and are present in both isoforms, granulin/epithelin precursors 1 and 2, identified in rodents (Plowman et al. 1992). Here, we show that the mink progranulin sequence for exons 1 and 2 share $86.6 \%$ of identity with the human sequence, $82.4 \%$ with the mouse sequence, and $94.9 \%$ with the dog sequence. Moreover, when the amino acid sequence alignment of mink, human, dog, and mouse partial progranulin protein was analyzed, it was seen that, in the mink partial sequence, all the cysteine residues were well conserved, as well as the serine, proline, and glycine residues shared by the 7.5 cysteine-rich motifs (Bhandari et al. 1992, Plowman et al. 1992). The presence of the wellconserved motifs of progranulin in the mink sequence suggests that the function of progranulin in mink parallels known functions in other species.

\section{Progranulin and endometrial gland proliferation}

During prolactin-mediated termination of embryonic diapause, progesterone is secreted by the corpus luteum and the consequent change in plasma progesterone concentration corresponds with a series of pre-implantation changes in the mink uterus (Moller 1973). We show progranulin mRNA and protein to be expressed in the luminal and glandular endometrial epithelium following prolactin-mediated reactivation of the uterus and embryo. Moreover, the high expression of progranulin in the glandular epithelial cells during the periimplantation transformation, and its lower expression in the transformed glands of the post-implantation period suggest that progranulin is involved in the implantationrelated epithelial cell transformations. The sustained strong expression of progranulin protein in the intact basal glands during all the stages examined suggests that progranulin is important for normal secretory activity of the endometrial glands. While progranulin protein is expressed in the transformed endometrial glands at the site of trophoblast apposition, the cognate progranulin mRNA expression is not observed. This suggests that the secretory and synthetic functions of the transformed glands are altered at the implantation site, in comparison with the intact glands.

\section{Progranulin and cytotrophoblast proliferation}

The present work followed the distribution of progranulin in the trophoblast on the day of implantation and through early post-implantation in vivo. Progranulin mRNA and protein expression are manifestly present in the mink cytotrophoblast during blastocyst adhesion and 

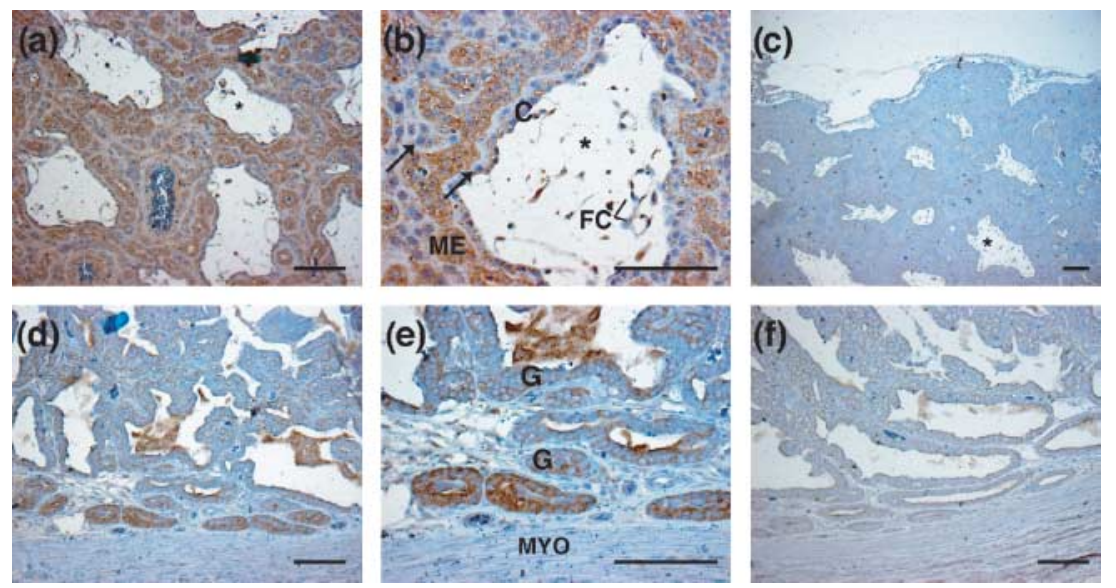

Figure 6 Progranulin protein is expressed in the trophoblast and the maternal hypertrophied endothelial cells in the early mink placenta. To detect progranulin protein by immunohistochemistry, $(a, b, d$ and e) the immune rabbit serum against human progranulin or (c and $f)$ the pre-immune rabbit serum (control) were employed. $(\mathrm{a}-\mathrm{c})$ Labyrinth of the early mink placenta (at day 5 following implantation). (a) High expression of progranulin protein is detected in many cell types of the labyrinth. (b) It is present in the cytotrophoblast and the syncytiotrophoblast, and highly expressed in the fetal capillaries of the mesenchymal core and in the maternal hypertrophied endothelial cells surrounding the fetal villi, as shown at higher magnification. ( $\mathrm{d}-\mathrm{f})$ Glandular zone of the early mink placenta. The immunostaining is strongly positive in the intact basal glands, and somewhat weaker in the epithelium of the transformed glands ( $d$ and e). E, luminal epithelium; G, glandular epithelium; C, cytotrophoblast; MYO,

myometrium; ME, maternal endothelial cells (maternal blood vessels); ${ }^{*}$ Chorionic villi comprising the fetal mesenchyme and fetal capillaries (FC), the cytotrophoblast, and the syncytiotrophoblast; arrows, syncytiotrophoblast. Bars: $100 \mu \mathrm{m}$.

syncytiotrophoblast penetration into the endometrial epithelium, and this is consistent with the high levels of progranulin transcripts found previously in the mouse post-adhesion blastocyst by cDNA microarray (Qin et al. 2003). Our data are also in accordance with the findings that progranulin promotes mouse trophoblast proliferation as well as blastocyst hatching, adhesion, and outgrowth in vitro (Diaz-Cueto et al. 2000, Qin et al. 2005). In mustelid species, the cytotrophoblast undergoes active cell division soon after implantation to achieve formation of the chorionic villi (Enders \& Schlafke 1972). Here, we show that progranulin expression remains elevated throughout the chorionic villi development during early gestation in the mink. Thus, our results argue for a role for progranulin in cytotrophoblast proliferation and migration during formation of the chorionic villi throughout early implantation and placentation in the mink.

\section{Progranulin and maternal endothelial cell proliferation}

Winther et al. (1999) described the neovascularization of the mink placenta at different stages of development. During early gestation, maternal endothelial cells undergo extensive mitosis. At mid-gestation, the vessel walls are remodeling and periendothelial cells appear; and at late gestation, the mitogenic activity of these endothelial cells is decreased. According to our data, progranulin is differentially expressed in the endothelial cells of the maternal blood vessels of the early implanted uterus, with stronger expression in the blood vessels nearby the transformed endometrial glands. These vessels are expected to be the newly formed blood vessels that will eventually irrigate the placental labyrinth. Our results reveal progranulin expression at high levels in the maternal hypertrophied endothelial cells of the incipient labyrinth. These results suggest that progranulin may play a role in angiogenesis, as has previously been reported in neovascularization during embryogenesis, tumorigenesis, and throughout the wound repair process (He \& Bateman 2003). Progranulin is usually absent from normal adult endothelial cells, but during wound repair, its expression is strongly induced in the endothelial cells at the site of the lesion (He et al. 2003). Moreover, progranulin promotes tubule-like structure formation of endothelial cells in vitro (He et al. 2003) and enhances vascular endothelial growth factor (VEGF) expression in breast cancer cells (Tangkeangsirisin \& Serrero 2004). Progranulin is also expressed in blood vessels surrounding invasive ovarian tumors (Jones et al. 2003) and during establishment of the microvasculature in the murine embryo (Daniel et al. 2003). We have previously shown that VEGF of embryo and stromal cell provenance to be strongly expressed during the implantation and early invasion in the mink (Lopes et al. 2003). Together, the morphological evidence for expression in tissues at a time when extensive revascularization and VEGF expression is taking place support a role for progranulin in neovascularization of the early placenta in the mink.

\section{The regulation and the role of progranulin during implantation in the mink}

Estrogen has previously been shown to stimulate the expression of progranulin in human breast cancer cells 
(Lu \& Serrero 1999), and progranulin was shown to mediate the mitogenic effects of estrogen in these cells (Lu \& Serrero 2001), even in the absence of a typical estrogen response element on the promoter of human and mouse progranulin genes (Baba et al. 1993a, 1993b, Bhandari et al. 1996). In the rodent model displaying a facultative delay of implantation, estrogen, in combination with progesterone, is the signal that initiates blastocyst implantation (Yoshinaga \& Adams 1966, Psychoyos 1973). Via the nuclear estrogenic receptor $(E R)$, estrogens can induce the expression of many growth factors and their receptors in the mouse uterus during implantation by activating the membrane-trafficking pathway (Chen et al. 1999). Moreover, early estrogenic responses can be observed in the presence of catechol-estrogen or xenoestrogens in the mouse uterus, independently of $E R \alpha / E R \beta$ (Das et al. 1997a, $1997 b)$, suggesting that the activation of nongenomic pathways can be responsible of an estrogenic response in the uterus, independently of nuclear ERs. The roles of estrogen in mink during implantation are not clear, but based on this evidence, it would be reasonable to speculate that estrogen or other estrogenic compounds are potential regulators of progranulin expression in the mink endometrium and trophectoderm.

The pattern of progranulin expression and activity is, in many ways, similar to that of other growth factors in the blastocyst and the uterus. For example, around the time of embryo implantation in the mouse, several members of the EGF family of growth factors are upregulated in the uterus, including EGF itself, TGF $\alpha$, HB-EGF, betacellulin, epiregulin, neuregulins, and amphiregulin (Das et al. 1997a, 1997b, Lim et al. 1998). The overlapping expression of several EGF family members in the endometrial epithelium around the time of implantation, and the absence of any defects in the implantation phenotype in targeted mice for EGF/ TGFa/amphiregulin in combination suggests that these growth factors play compensatory roles in the uterus (reviewed by Dey et al. 2004). In addition, consistent with the effects of progranulin on mouse blastocysts (Diaz-Cueto et al. 2000, Qin et al. 2005), HB-EGF promotes development and hatching of human blastocysts in vitro (Martin et al. 1998). Together, these findings suggest that the role of progranulin is redundant with the roles exerted by other similar growth factors during mink implantation. In summary, this report demonstrates the spatiotemporal distribution of progranulin mRNA and protein for the first time at the time of embryo implantation and early placenta development in vivo. Progranulin expression is mainly associated with epithelial hypertrophy and proliferation in the endometrium, with cytotrophoblast proliferation and migration, and with maternal angiogenesis in the endotheliochorial placenta. Therefore, we suggest that high levels of progranulin expression indicate that this protein plays a role in cell proliferation, remodeling, and angiogenesis which occur during the establishment of the placenta in the mink.

\section{Materials and Methods}

\section{Animals}

Primiparous and multiparous Pastel and Dark female ranch mink (Mustela vison) were purchased from Mr A Richard (St. Damase, QC, Canada) and were bred according to usual commercial farming procedures. The biological samples were collected during the normal breeding season in March. All procedures involving live animals were submitted to, and approved by, the Comité d'éthique de l'utilization des animaux, Faculté de Médecine Vétérinaire, Université de Montréal, and were in accordance with the Canadian Council on Animal Care guidelines. To terminate pre-implantation delay, $1 \mathrm{mg} / \mathrm{kg}$ per day ovine prolactin (Sigma) was administered i.m. daily to the animals, for 11 days, after which implantation occurs (Desmarais et al. 2004). Uterine tissues and implantation sites were collected after 9 days of prolactin treatment, and $0,1,2$, or 5 days after implantation in experimental groups representing the pre- and early postimplantation periods. The tissues were flash frozen in liquid nitrogen for RNA preservation, or fixed overnight with $4 \%(\mathrm{w} / \mathrm{v})$ paraformaldehyde (PFA) in PBS ( $\mathrm{pH} 7.4)$, rinsed three times overnight in PBS, and processed for paraffin embedding. Tissues were sectioned at $5 \mu \mathrm{m}$ for in situ hybridization or immunohistochemistry.

\section{Cloning of mink partial cDNA sequence}

Total RNA was isolated from mink uterine tissues including the implantation site, with the RNeasy mini kit (Qiagen). The isolated RNA was treated with RNase-free DNase 1 (Ambion, Austin, TX, USA) to remove DNA, and cognate cDNA produced by employing the Superscript II Reverse Transcriptase enzyme (Invitrogen), following the manufacturer's instructions. A PCR was conducted with canine-specific progranulin primers to amplify a mink progranulin partial cDNA sequence. The forward primer sequence is $5^{\prime}$-AGA TGG TCA GTT CTG CCC TGT G-3' and the reverse primer sequence is $5^{\prime}$-ACA CGA CAC GGC CTC TGG GAA-3'. For PCR, $1 \cup$ Taq DNA polymerase (Invitrogen) was used per $\mu$ g of DNA in a $20 \mu \mathrm{I}$ PCR, and the amplification was conducted in a PTC-200 Peltier thermal cycler (MJ Research, Watertown, MA, USA), programmed for an initial denaturation step at $94{ }^{\circ} \mathrm{C}$ for $3 \mathrm{~min}$, followed by 35 cycles of $95{ }^{\circ} \mathrm{C}$ for $30 \mathrm{~s}, 56^{\circ} \mathrm{C}$ for $30 \mathrm{~s}$, and $72{ }^{\circ} \mathrm{C}$ for $30 \mathrm{~s}$, and a final elongation step at $72{ }^{\circ} \mathrm{C}$ for $3 \mathrm{~min}$. The $214 \mathrm{bp}$ PCR fragment was purified from an agarose gel using an extraction kit (Qiagen), ligated into a pDrive cloning vector (Qiagen) and the clones were amplified in an XL1-blue bacterial strain. The amplified plasmids were purified with a Qiaprep spin miniprep kit (Qiagen) and digested with EcoRI (GE Healthcare, Baie d'Urfé, QC, Canada) to confirm the presence of the insert. The purified plasmid was sequenced with an automated sequencer by the Services d'analyze et de synthèse SCF, Université Laval (Québec, QC, Canada), to confirm the identity of the PCR product. Multiple sequence alignment was conducted 
with DNasis v2.0 software (Hitachi Software Engineering, Yokohama, Japan), and the percentage of homology was calculated thereafter. Amino acid alignment was performed using the CLC Sequence Viewer software 4.6.1 (CLC bio A/S, Aarhus $C$, Denmark). The accession numbers of the sequences used for the alignments can be found in GenBank as follows: human NM_002087/NP_002078; dog XM_537620/ XP_537620; and mouse NM_008175/NP_032201. The mink partial progranulin coding sequence and deduced amino acid sequence were entered in GenBank (accession number EF566010/ABQ_44207).

\section{In situ hybridization}

Human-specific digoxygenin-UTP-labeled progranulin RNA sense and antisense probes of $237 \mathrm{bp}$ were generated as described (Daniel et al. 2000). In situ hybridization was carried out as in Daniel et al. (2000) with modifications. Paraffin sections were deparaffinized in Citrosolv (Fisher, Whitby, ON, Canada) and rehydrated in a graded series of ethanol. Tissues were post-fixed in $4 \%$ PFA ( $\mathrm{pH} 7.4$, Fisher) and washed with $0.5 \times$ SSC buffer. Permeabilization of the tissue was carried out by incubation with $0.2 \mathrm{M} \mathrm{HCl}$ for $5 \mathrm{~min}$ and followed by incubation with proteinase $\mathrm{K}(3.5 \mu \mathrm{g} / \mathrm{ml})$ in $100 \mathrm{mM}$ Tris- $\mathrm{HCl}$ and $50 \mathrm{mM}$ EDTA buffer ( $\mathrm{pH} 8.0$ ), at $37{ }^{\circ} \mathrm{C}$ for $15 \mathrm{~min}$. Another post-fixation step with $4 \%$ PFA was conducted and slides were washed thoroughly with PBS and $0.5 \times$ SSC. The sections were then pre-hybridized for $3 \mathrm{~h}$ in hybridization solution $(5 \times \mathrm{SSC}$, $5 \times$ Denhardt's solution), $50 \%(\mathrm{v} / \mathrm{v})$ deionized formamide (Bioshop, Burlington, ON, Canada), and $250 \mu \mathrm{g} / \mathrm{ml}$ tRNA (Roche), and hybridized with $75 \mathrm{ng}$ digoxygenin-UTP-labeled RNA probes for $18 \mathrm{~h}$ at $42{ }^{\circ} \mathrm{C}$. After stringency washing with different concentrations of SSC at $50^{\circ} \mathrm{C}$, sections were blocked with $1 \%$ of Blocking Reagent (Roche) in $1 \mathrm{M}$ maleic acid and $0.15 \mathrm{M} \mathrm{NaCl}$ buffer $(\mathrm{pH} 7.5)$, and were incubated with $750 \mathrm{mU} / \mathrm{ml}$ anti-digoxigenin-AP-conjugated antibody (Roche). The unbound antibody conjugate was washed off and sections were incubated with freshly prepared NBT-BCIP color substrate (Roche) in a $100 \mathrm{mM}$ Tris and $100 \mathrm{mM} \mathrm{NaCl}$ solution ( $\mathrm{pH}$ 9.5), until the desired signals were obtained. The reaction products were visualized with a brightfield Leica AS LMD microscope (Leica Microsystems Inc., Wetzlar, Germany). For each sample, two successive slides were incubated either with sense or antisense probe to monitor non-specific hybridization signal.

\section{Immunohistochemistry}

Immunohistochemistical localization of mink progranulin protein was carried out using antiserum from a rabbit immunized against the full-length progranulin coding sequence, generated in house. The recombinant progranulin full-length fragment was expressed in a baculovirus expression system and purified to homogeneity before immunization. The resulting polyclonal antibody reacts with human, mouse, rat, and porcine progranulin in comparative immunohistochemical evaluation. It recognizes multiple individual $6 \mathrm{kDa}$ granulin/epithelin proteolytic peptides, but only weakly. The sections were deparaffinized in Citrosolv (Fisher) and rehydrated in a graded series of ethanol. Antigen retrieval was performed by boiling the slides in a $10 \mathrm{mM}$ sodium citrate solution for $20 \mathrm{~min}$ in a microwave oven. Dako LSAB2 Systemhorseradish peroxidase (HRP) kits (DakoCytomation, Carpinteria, CA, USA) were employed following the manufacturer's recommended protocol. Briefly, endogenous peroxidases were blocked with $3 \%(\mathrm{v} / \mathrm{v})$ peroxide solution for $30 \mathrm{~min}$ and sections were treated with $3 \%$ BSA and $0.1 \%(\mathrm{v} / \mathrm{v})$ Tween-20 in PBS for $3 \mathrm{~h}$ at room temperature to block the non-specific binding, and thereafter, were incubated with rabbit-antiserum against human progranulin, diluted 1:100 in antibody diluent (DakoCytomation), in a humidified chamber, over night at $4{ }^{\circ} \mathrm{C}$. The biotinylated secondary antibody, streptavidin-HRP, and diaminoabenzadine (DAB) substrate were subsequently employed for signal visualization, according to the manufacturer's (DakoCytomation) recommended protocol. Between steps, sections were washed three times for $3 \mathrm{~min}$. Finally, brown precipitate was observed at the antigen site and the sections were briefly counterstained with Harris modified hematoxylin (Fisher). Before mounting, sections were dehydrated in the series of ethanol. In the control slides, rabbit antiserum against progranulin incubation was replaced by a pre-immune rabbit serum incubation. The signals were visualized with a brightfield Leica AS LMD microscope (Leica Microsystems Inc).

\section{Declaration of interest}

The authors have no real or potential conflicts of interest to declare with entities related to the material being published.

\section{Funding}

This work was supported by a Discovery Grant from the Natural Sciences and Engineering Research Council of Canada to B D $M$ and an Operating Grant from the Canadian Institute for Health Research to A B.

\section{Acknowledgements}

The authors acknowledge the participation of Ricardo R Guerra for its assistance with immunohistochemistry, Simon-Pierre Demers for the preparation of this manuscript, Mira DobiasGoff for the technical support, and Flavia L Lopes for sample collection.

\section{References}

Baba T, Hoff HB III, Nemoto H, Lee H, Orth J, Arai Y \& Gerton GL 1993a Acrogranin, an acrosomal cysteine-rich glycoprotein, is the precursor of the growth-modulating peptides, granulins, and epithelins, and is expressed in somatic as well as male germ cells. Molecular Reproduction and Developement 34 233-243.

Baba T, Nemoto H, Watanabe K, Arai Y \& Gerton GL $1993 b$ Exon/intron organization of the gene encoding the mouse epithelin/granulin precursor (acrogranin). FEBS Letters 322 89-94.

Backlin BM, Persson E, Jones CJ \& Dantzer V 1998 Polychlorinated biphenyl (PCB) exposure produces placental vascular and trophoblastic 
lesions in the mink (Mustela vison): a light and electron microscopic study. Acta Pathologica, Microbiologica, et Immunologica Scandinavica 106 785-799.

Baker M, Mackenzie IR, Pickering-Brown SM, Gass J, Rademakers R, Lindholm C, Snowden J, Adamson J, Sadovnick AD, Rollinson S et al. 2006 Mutations in progranulin cause tau-negative frontotemporal dementia linked to chromosome 17. Nature 442 916-919.

Bateman A \& Bennett HP 1998 Granulins: the structure and function of an emerging family of growth factors. Journal of Endocrinology 158 145-151.

Bhandari V, Palfree RG \& Bateman A 1992 Isolation and sequence of the granulin precursor cDNA from human bone marrow reveals tandem cysteine-rich granulin domains. PNAS 89 1715-1719.

Bhandari V, Giaid A \& Bateman A 1993 The complementary deoxyribonucleic acid sequence, tissue distribution, and cellular localization of the rat granulin precursor. Endocrinology 133 2682-2689.

Bhandari V, Daniel R, Lim PS \& Bateman A 1996 Structural and functional analysis of a promoter of the human granulin/epithelin gene. Biochemical Journal 319 441-447.

Chen D, Ganapathy P, Zhu LJ, Xu X, Li Q, Bagchi IC \& Bagchi MK 1999 Potential regulation of membrane trafficking by estrogen receptor alpha via induction of rab11 in uterine glands during implantation. Molecular Endocrinology 13 993-1004.

Cruts M, Gijselinck I, van der Zee J, Engelborghs S, Wils H, Pirici D, Rademakers R, Vandenberghe R, Dermaut B, Martin JJ et al. 2006 Null mutations in progranulin cause ubiquitin-positive frontotemporal dementia linked to chromosome 17q21. Nature 442 920-924.

Daniel R, He Z, Carmichael KP, Halper J \& Bateman A 2000 Cellular localization of gene expression for progranulin. Journal of Histochemistry and Cytochemistry 48 999-1009.

Daniel R, Daniels E, He Z \& Bateman A 2003 Progranulin (acrogranin/PC cell-derived growth factor/granulin-epithelin precursor) is expressed in the placenta, epidermis, microvasculature, and brain during murine development. Developmental Dynamics 227 593-599.

Das SK, Das N, Wang J, Lim H, Schryver B, Plowman GD \& Dey SK 1997a Expression of betacellulin and epiregulin genes in the mouse uterus temporally by the blastocyst solely at the site of its apposition is coincident with the 'window' of implantation. Developmental Biology 190 178-190.

Das SK, Taylor JA, Korach KS, Paria BC, Dey SK \& Lubahn DB 1997 b Estrogenic responses in estrogen receptor-alpha deficient mice reveal a distinct estrogen signaling pathway. PNAS 94 12786-12791.

Desmarais JA, Bordignon V, Lopes FL, Smith LC \& Murphy BD 2004 The escape of the mink embryo from obligate diapause. Biology of Reproduction 70 662-670.

Dey SK, Lim H, Das SK, Reese J, Paria BC, Daikoku T \& Wang H 2004 Molecular cues to implantation. Endocrine Reviews 25 341-373.

Diaz-Cueto L, Stein P, Jacobs A, Schultz RM \& Gerton GL 2000 Modulation of mouse preimplantation embryo development by acrogranin (epithelin/granulin precursor). Developmental Biology 217 406-418.

Donald CD, Laddu A, Chandham P, Lim SD, Cohen C, Amin M, Gerton GL, Marshall FF \& Petros JA 2001 Expression of progranulin and the epithelin/granulin precursor acrogranin correlates with neoplastic state in renal epithelium. Anticancer Research 21 3739-3742.

Duby RT \& Travis HF 1972 Photoperiodic control of fur growth and reproduction in the mink (Mustela vison). Journal of Experimental Zoology 182 217-226.

Enders RK 1952 Reproduction in the mink (Mustela vison). Proceedings of the American Philosophical Society 96 691-755.

Enders AC \& Mead RA 1996 Progression of trophoblast into the endometrium during implantation in the western spotted skunk. Anatomical Record 244 297-315.

Enders AC \& Schlafke S 1972 Implantation in the ferret: epithelial penetration. American Journal of Anatomy 133 291-315.

Gulamhusein AP \& Beck F 1973 Light and electron microscope observations at the pre- and early post-implantation stages in the ferret uterus. Journal of Anatomy 115 159-174.

Gulamhusein AP \& Beck F 1975 Development and structure of the extraembryonic membranes of the ferret. A light microscopic and ultrastructural study. Journal of Anatomy 120 349-365.

Hansson A 1947 The physiology of reproduction in the mink (Mustela vison Schreb.) with special reference to delayed implantation. Acta Zoologica 28 1-136.
He Z \& Bateman A 2003 Progranulin (granulin-epithelin precursor, PC-cellderived growth factor, acrogranin) mediates tissue repair and tumorigenesis. Journal of Molecular Medicine 81 600-612.

He Z, Ismail A, Kriazhev L, Sadvakassova G \& Bateman A 2002 Progranulin (PC-cell-derived growth factor/acrogranin) regulates invasion and cell survival. Cancer Research 62 5590-5596.

He Z, Ong CH, Halper J \& Bateman A 2003 Progranulin is a mediator of the wound response. Nature Medicine 9 225-229.

Hrabal R, Chen Z, James S, Bennett HP \& Ni F 1996 The hairpin stack fold, a novel protein architecture for a new family of protein growth factors. Nature Structural Biology 3 747-752.

Jones CJ, Dantzer V, Leiser R, Krebs C \& Stoddart RW 1997 Localisation of glycans in the placenta: a comparative study of epitheliochorial, endotheliochorial, and haemomonochorial placentation. Microscopy Research and Technique 38 100-114.

Jones MB, Michener CM, Blanchette JO, Kuznetsov VA, Raffeld M, Serrero G, Emmert-Buck MR, Petricoin EF, Krizman DB, Liotta LA et al. 2003 The granulin-epithelin precursor/PC-cell-derived growth factor is a growth factor for epithelial ovarian cancer. Clinical Cancer Research 9 44-51.

Krebs C, Winther H, Dantzer V \& Leiser R 1997 Vascular interrelationships of near-term mink placenta: light microscopy combined with scanning electron microscopy of corrosion casts. Microscopy Research Technique 38 125-136.

Liau LM, Lallone RL, Seitz RS, Buznikov A, Gregg JP, Kornblum HI, Nelson SF \& Bronstein JM 2000 Identification of a human gliomaassociated growth factor gene, granulin, using differential immunoabsorption. Cancer Research 60 1353-1360.

Lim H, Das SK \& Dey SK 1998 erbB genes in the mouse uterus: cell-specific signaling by epidermal growth factor (EGF) family of growth factors during implantation. Developmental Biology 204 97-110.

Lopes FL, Desmarais J, Gevry NY, Ledoux S \& Murphy BD 2003 Expression of vascular endothelial growth factor isoforms and receptors Flt-1 and KDR during the peri-implantation period in the mink (Mustela vison). Biology of Reproduction 68 1926-1933.

Lopes FL, Desmarais JA \& Murphy BD 2004 Embryonic diapause and its regulation. Reproduction 128 669-678.

Lu R \& Serrero G 1999 Stimulation of PC cell-derived growth factor (epithelin/granulin precursor) expression by estradiol in human breast cancer cells. Biochemical and Biophysical Research Communications 256 204-207.

Lu R \& Serrero G 2001 Mediation of estrogen mitogenic effect in human breast cancer MCF-7 cells by PC-cell-derived growth factor (PCDGF/granulin precursor). PNAS 98 142-147.

Martin KL, Barlow DH \& Sargent IL 1998 Heparin-binding epidermal growth factor significantly improves human blastocyst development and hatching in serum-free medium. Human Reproduction 13 1645-1652.

Martinet L, Allais C \& Allain D 1981 The role of prolactin and LH in luteal function and blastocyst growth in mink (Mustela vison). Journal of Reproduction and Fertility 29 119-130.

Moller OM 1973 The progesterone concentrations in the peripheral plasma of the mink (Mustela vison) during pregnancy. Journal of Endocrinology 56 121-132.

Murphy BD \& James DA 1974 The effects of light and sympathetic innervation to the head on nidation in mink. Journal of Experimental Zoology 187 267-276.

Murphy BD, Concannon PW, Travis HF \& Hansel W 1981 Prolactin: the hypophyseal factor that terminates embryonic diapause in mink. Biology of Reproduction 25 487-491.

Murphy BD, Mead RA \& McKibbin PE 1983 Luteal contribution to the termination of preimplantation delay in mink. Biology of Reproduction 28 497-503.

Papke RL, Concannon PW, Travis HF \& Hansel W 1980 Control of luteal function and implantation in the mink by prolactin. Journal of Animal Science 50 1102-1107.

Plowman GD, Green JM, Neubauer MG, Buckley SD, McDonald VL, Todaro GJ \& Shoyab M 1992 The epithelin precursor encodes two proteins with opposing activities on epithelial cell growth. Journal of Biological Chemistry 267 13073-13078.

Psychoyos A 1973 Hormonal control of ovoimplantation. Vitamins and Hormones 31 201-256. 
Qin J, Takahashi Y, Imai M, Yamamoto S, Takakura K, Noda Y \& Imakawa K 2003 Use of DNA array to screen blastocyst genes potentially involved in the process of murine implantation. Journal of Reproduction and Development 49 473-484.

Qin J, Diaz-Cueto L, Schwarze JE, Takahashi Y, Imai M, Isuzugawa K, Yamamoto S, Chang KT, Gerton GL \& Imakawa K 2005 Effects of progranulin on blastocyst hatching and subsequent adhesion and outgrowth in the mouse. Biology of Reproduction 73 434-442.

Steven DH 1975 Anatomy of the placental barrier. In Comparative Placentation: Essays in structure and function, pp 25-57. Eds RJ Harrison \& AW Asscher. New York: Academic Press.

Sundqvist C, Ellis LC \& Bartke A 1988 Reproductive endocrinology of the mink (Mustela vison). Endocrine Reviews 9 247-266.

Suzuki M \& Nishiahara M 2002 Granulin precursor gene: a sex steroidinducible gene involved in sexual differentiation of the rat brain. Molecular Genetics and Metabolism 75 31-37.

Tangkeangsirisin W \& Serrero G 2004 PC cell-derived growth factor (PCDGF/GP88, progranulin) stimulates migration, invasiveness and VEGF expression in breast cancer cells. Carcinogenesis 25 1587-1592.

Tangkeangsirisin W, Hayashi J \& Serrero G 2004 PC cell-derived growth factor mediates tamoxifen resistance and promotes tumor growth of human breast cancer cells. Cancer Research 64 1737-1743.
Winther H, Leiser R, Pfarrer C \& Dantzer V 1999 Localization of microand intermediate filaments in non-pregnant uterus and placenta of the mink suggests involvement of maternal endothelial cells and periendothelial cells in blood flow regulation. Anatomy and Embryology 200 $163-253$.

Yoshinaga K \& Adams CE 1966 Delayed implantation in the spayed, progesterone treated adult mouse. Journal of Reproduction and Fertility 12 593-595.

Zanocco-Marani T, Bateman A, Romano G, Valentinis B, He ZH \& Baserga R 1999 Biological activities and signaling pathways of the granulin/epithelin precursor. Cancer Research 59 5331-5340.

Zhou J, Gao G, Crabb JW \& Serrero G 1993 Purification of an autocrine growth factor homologous with mouse epithelin precursor from a highly tumorigenic cell line. Journal of Biological Chemistry $\mathbf{2 6 8}$ 10863-10869.

Received 28 January 2008

First decision 26 February 2008

Revised manuscript received 6 April 2008

Accepted 6 May 2008 